\title{
Perceptions of Positive Relationship Traits in Gay and Lesbian Couples
}

\author{
Miki D. Skinner: McNair Scholar \\ Dr. Wind Goodfriend: Mentor
}

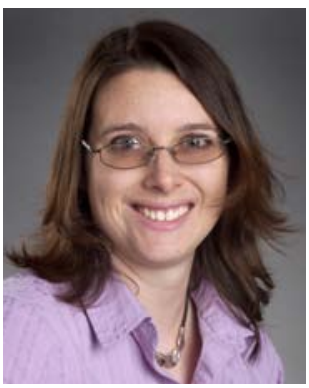

Psychology

\begin{abstract}
The following study examined perceptions of positive traits in homosexual relationships. Students $(n=216)$ and professional counselors $(n=96)$ read one of three variations of a transcript of a couple's counseling session that were identical in all aspects except for the names of the couple members and associated pronouns, implying sexual orientation (either John and Amy, Amy and Jennifer, or John and David). Participants then rated the couple's level of commitment, satisfaction, investment, and closeness. Surprisingly, the student group perceived no differences between the couples, but the counselor group perceived the gay and lesbian couples as having higher levels of the positive relationship traits. Implications regarding counselor bias are discussed.
\end{abstract}

\section{Introduction}

In an ideal world, an individual or group of individuals would always be assessed based on their own personal attributes and actions. Unfortunately, however, this is not always the case, especially for those individuals belonging to an outgroup $11,17,21,30$. This tendency affects all areas of life, but psychological research has tended to focus on ingroup versus outgroup distinctions based on race, skin color, gender, religious affiliation, age, disability, and sexual orientation.

The research regarding sexual orientation has grown steadily over the last century. Kinsey and associates were certainly a catalyst in this field when they began to examine human sexuality in general in the middle of the last century ${ }^{14,17}$. Their findings that homosexual acts and thoughts were far more common than previously believed rocked American society. Their research took the notion of sexual orientation from a dichotomous field with a minute minority falling in the homosexual category, and expanded it to a prism where total heterosexuality and homosexuality were the minorities and everyone else fell somewhere in between. Although much of the current culture may still tend to believe in the dichotomous model, the work done by Kinsey opened up a new venue in which researchers could begin to explore not just homosexuality, but society's view of homosexuality $7,18,22$.

Prejudice based on sexual orientation is a growing area of study $10,16,24$. It is not surprising to find that patterns of prejudice towards gays, lesbians, and bisexuals follow the general pattern of prejudice over all. Jellison and colleagues found that in heterosexual male participants, there was a negative correlation between attitudes toward heterosexuality and attitudes toward homosexuality, showing the common practice of ingroup versus outgroup bias ${ }^{16}$. Prejudice relevant to sexual orientation is a function of both negative preconception and simple ignorance. For example, in 1997, Eliason found that a large percentage of participants were generally ignorant when it came to stereotypes and social concerns that both involved and affected bisexuals ${ }^{10}$.

The majority of this research has focused on prejudices and attitudes towards non-heterosexual orientations in general. In order to better understand these overlying biases it is important to take a closer look at more specific areas of perception affected by prejudice. The current political climate regarding gay and lesbian relationships makes such research even more valuable. As social scientists, it is important to understand not only the true nature of non-heterosexual relationships, but also the way in which the general populace perceives those relationships.

The current study examines individuals' perception of commitment, satisfaction, investment, and closeness in a non-heterosexual relationship as compared with a heterosexual relationship. Previous research has shown that, in general, gay and lesbian relationships are no less satisfying, close, or well-adjusted than are heterosexual relationships. In 1978, gay, lesbian, and heterosexual couples were compared on a measure of "marital" adjustment, and no distinguishable differences were found between the groups ${ }^{28}$. Other research has found similar results, with gay and lesbian relationships having no significant differences in relationship satisfaction, compared to heterosexuals ${ }^{8,27}$. When it comes to relationship commitment, there is less extant research, but that which has been 
done does not suggest either more or less commitment in homosexual couples, and it is likely that emotional qualities related to relationship commitment are similar in both heterosexual and homosexual couples 5, 12, 19,26. However, this may not be the commonly held view among the general populace, and may also differ in regards to perceptions of gay males as opposed to lesbians. In 2002, Hewitt and Moore found that there were different constructs of homosexuality regarding lesbians and gay males, stating that, "It would seem prudent, then, that researchers avoid conducting research in which homosexuality is used generically to refer to both lesbians and gay men, as beliefs about lesbians and gay men may well differ" (p. 70) ${ }^{13}$.

In the current study it was expected that gay, lesbian, and heterosexual couples would be perceived to have different levels of commitment, satisfaction, investments, and closeness, based only on the sexual orientation of the couple. Because previous research has noted that gay males are perceived as being less emotionally involved in their relationships ${ }^{5,20}$, it was expected that the gay male couple would be perceived as having the least amount of commitment, satisfaction, investments, and closeness. The lesbian couple was expected to be perceived slightly more favorably, with the heterosexual couple being perceived as having the greatest amount of the aforementioned qualities.

Commitment is the subjective state of dependence that individuals experience daily regarding their relationship ${ }^{2}$. Commitment is hypothesized to be a function of three interrelated factors: (1) the level of satisfaction with the relationship (or the degree to which a relationship is experienced as gratifying); (2) the quality of a relationship's alternatives (or the perceived desirability of the best available alternative to the current relationship), and (3) the size of investments in the relationship. Investment size is defined as "the magnitude and importance of the resources that are attached to a relationship - resources that would decline in value or be lost if the relationship were to end" ${ }^{29}$. Closeness is defined as "people's sense of interpersonal interconnectedness" (p. 597) ${ }^{3}$.

As with many psychological studies, the initial participant group in this research was made up of students attending a metropolitan university. It was expected that some amount of bias against non-heterosexual couples would be found in this population. However, certain subgroups within the American culture are expected to be less biased in their views towards others. Because of specific ethics and sensitivity training, professional counselors and therapists are expected to fall into this category ${ }^{13,15}$. It is important that this expectation hold true because the nature of the helping professions, such as counseling, demands a significant level of trust and understanding between the client and the therapist ${ }^{9}$. Unfortunately, past studies have found that this is not always the case ${ }^{23}$. Although the primary hypothesis of this study was that perception of commitment, satisfaction, investments, and closeness in nonheterosexual couples would be lower than the levels perceived in heterosexual relationships, it was also expected that professional counselors would perceive less of a difference between the control and experimental groups as compared to the difference perceived by the student group.

One must also recognize that there are numerous other factors that may affect an individual's response to the relationships of others, especially different others. One such area is that person's desire to be socially acceptable 6,25 . Current social norms teach us that there are certain behaviors and beliefs that are beneficial for us to conform to if we wish to participate and be accepted in society. At times an individual's personal beliefs may contradict these socially accepted beliefs, but that individual will attest to holding those beliefs in order to appear acceptable to others. Sexual orientation tends to be a volatile and somewhat taboo subject in the American culture, while at the same time gaining support in political circles to combat prejudice. Because of this duality, participants' desire to appear socially acceptable should be assessed.

\section{Hypotheses}

To summarize, three major hypotheses were made in the current study. Hypothesis 1: It was expected that for perceived levels of commitment, satisfaction, investments, and closeness, college students would perceive the gay couple as having the lowest levels of the qualities, the lesbian couple as having slightly more, and the heterosexual couple as having the highest. Hypothesis 2: Conversely, no significant differences in the experimental groups were expected to be found when testing professional counselors. Hypothesis 3: It was anticipated that there would be a significant difference in the levels of commitment, satisfaction, investments, and closeness in the gay male and lesbian group as perceived by the student population compared to that of the counselor population.

\section{Method}

\section{Participants}

This study included two separate participant groups. The initial participant group consisted of 216 undergraduate students attending a metropolitan research university in the Northwestern United States. The students were enrolled in a general psychology course and were given the option to participate in ongoing research to fulfill 
partial course credit. The demographic break down of the participants was as follows: 109 of the participants identified as female, and 107 identified as male. The participants were asked to identify their race or ethnicity; $81 \%$ identified as White, $6 \%$ as Hispanic, $1 \%$ as Black, $2 \%$ as Asian, and $11 \%$ as other or did not respond. The mean age of the participants was 20.6 years $(S D=4.4)$ with a range from 18 years to 51 years. The participants' current romantic relationship status was assessed; $46 \%$ were currently single, $6 \%$ were dating more than one person, $30 \%$ were dating one person, $4 \%$ were engaged, $7 \%$ were cohabiting with their romantic partner, $6 \%$ were married, and $1 \%$ declined to answer. In response to the extended sexual orientation scale, 65 of the male students identified as exclusively heterosexual, 1 as exclusively homosexual, and 41 had mixed responses. For the female students, 64 identified as exclusively heterosexual, 3 as exclusively homosexual, and 42 had mixed responses.

The second participant group consisted of professional counselors and therapists from the Northwestern United States. Participants were contacted through the name and address published in the public business phone directory. Surveys were mailed to 1,000 counselors and therapists, of which 96 responded by returning the completed survey, for a response rate of $9.6 \%$. The demographic breakdown of this group is as follows: 61 of the participants identified as female, and 35 identified as male. When identifying their race or ethnicity, $93 \%$ identified as Caucasian, $1 \%$ identified as Native American, $1 \%$ identified as Hispanic, and 5\% did not respond. The mean age of the participants in the second group was 55 years $(S D=8.04)$ with a range from 33 years to 74 years. The participants' current romantic relationship status was assessed; $4 \%$ were currently single, $3 \%$ were dating one person, $3 \%$ were engaged, $5 \%$ were cohabitating with their romantic partner, $67 \%$ were married, $17 \%$ were divorced, separated, or widowed, and 1\% declined to answer. For sexual orientation, 18 of the male counselors identified as exclusively heterosexual, 17 had mixed responses, and none responded as exclusively homosexual. For the female counselors, 21 identified as exclusively heterosexual, 3 as exclusively homosexual, and 37 had mixed responses.

The second group was asked two additional demographic questions. They were asked to identify which professional licenses they held; 9 held a LPC, 15 a LCPC, 9 a LMFT, and 37 a LCSW, 17 held a Ph.D. or Psy.D., and 11 of the respondents held other licenses. It should also be noted that $8.33 \%$ held multiple licenses. The participants were also asked how long they had been in practice. The mean time was 20 years $(S D=8.67)$, ranging from 3 to 40 years.

\section{Materials}

Independent variable. Participants were asked to read an excerpt from a fictional couple's initial counseling session. Participants randomly received one of three variations of the transcript that were identical in all aspects except for the names of the couple members and associated pronouns. The control group (student group $n=72$, counselor group $n=27$ ) read about a couple with the names Jennifer and David. The first experimental group (student group $n=73$, counselor group $n=36$ ) read about a couple with the names John and David, and the second experimental group (student group $n=71$, counselor group $n=33$ ) read about a couple with the names Jennifer and Amy. The names used in the transcript were chosen from the most popular names for children born from 1974 to 1984 as listed by the Social Security Administration ${ }^{31}$. The four names used were also chosen because of their gender specificity in order to accentuate the perception that the couple was either heterosexual, gay, or lesbian.

The transcript was brief, and in it the issues addressed by the couple include general, mild dissatisfaction with the relationship. An example of a conflict experienced by the couple was given. The example involved one partner prioritizing a career opportunity over a five-year anniversary celebration, and feeling that (s)he would be accused of infidelity.

A pre-test asked four professional counselors whether the fictional transcript appeared realistic. Each of the counselors who were asked to review the transcript was licensed to practice counseling and therapy in the state in which the research was developed. They held varying degrees of higher learning; two held Ph.D.s, one held a Psy.D., and one held a M.A. All four counselors attested to the transcript's seeming authenticity.

After they read the transcript, all participants were asked to write a short response to two questions about the couple's relationship. First, they were asked to write about what they felt the major issue or issues were in the relationship. Second they were asked what, if anything, the couple could do to overcome them.

Dependent variables. To measure perceived commitment, satisfaction, and investment, the participants responded to a seventeen item assessment that was a modified version of the Rusbult, Martz, and Agnew scale 29 . The original scale has all items in first person (e.g., "My relationship is close to ideal"); the modified version used in the current study changed all items to refer to the couple from the transcript and asked the participants what they believed the likelihood of the statements was (e.g., "How likely is it that this couple has a relationship that is close to 
their ideal?"). Participants responded to the items on a 7-point Likert scale ranging from 1 (very unlikely) to 7 (very likely). There were seven items assessing commitment, five items for satisfaction, and five items for investments. Internal consistency for the composite measures was very good (alpha $=.83$ for commitment, .85 for satisfaction, and .80 for investments).

The participants were next presented with the Inclusion of Other in Self Scale (IOS) pictograph representing seven different levels of interconnectedness, or relationship closeness. The scale uses seven pictographs of two circles that grow consecutively closer, so a rating of 1 (choosing the two circles that are barely touching) indicates the least amount of closeness, and a rating of 7 (choosing the two circles that are nearly on top of one another) indicates the greatest level of closeness. Participants were asked to circle the image they felt most accurately described the relationship of the couple about whom they had read ${ }^{3}$. Demographic questions were then asked. Participants responded to questions regarding their age, gender, race/ethnicity, and relationship status, and in the counselor group licenses held, and length of time in practice.

Finally the participants responded to a forty-question social desirability scale ${ }^{25}$. Responses were on a 7point Likert scale ranging from 1 (not true) to 7 (very true). Examples of the questions asked include, "I have said something bad about a friend behind his or her back" and, "I never regret my decisions." Internal consistency for the social desirability measures was good (alpha $=.70$ for self deception, and .79 for impression management).

\section{Procedure}

For the student participant group the survey occurred in a classroom setting. The participants were given 60 minutes to complete the full survey. Most participants completed the survey within 15 minutes. Following the conclusion of the survey the participants were thanked for their time and debriefed regarding the nature of the study.

The participant group consisting of professional counselors was mailed the survey along with a cover letter and standard consent information. The cover letter invited the recipient to participate in the enclosed survey to help the researchers better understand perceptions of people in relationships. They were also informed that in order to complete the research, the researchers require professional counselors to complete the survey. The letter directed the recipient to contact the researchers if he or she wished to be debriefed on the full nature of the research. One participant contacted the researchers and requested a report of the results of the research; this was provided.

\section{Results}

\section{Hypothesis 1}

The first hypothesis expected that for perceived levels of commitment, satisfaction, investments, and closeness, student participants would perceive the gay couple as having the lowest levels of the qualities, the lesbian couple perceived as having slightly more, and the heterosexual couple perceived as having the highest levels. A series of one-way analyses of variance were conducted to test Hypothesis 1, one test for each of the four dependent variables (commitment, satisfaction, investment, and closeness). No significant differences were found in commitment, $F(2,214)=1.03, p=0.36$, satisfaction, $F(2,215)=0.12, p=0.89$, or investment, $F(2,214)=0.03, p=$ 0.97. As previously mentioned, perception of closeness was measured using the Inclusion of the Other in Self Scale (IOS). As with the other dependent variables in the student group, these means were not significantly different, $F(2$, $213)=0.55, p=0.58$. Thus, Hypothesis 1 was not supported. For means and standard deviations on all four of the dependent variables for both the counselor and student group, please refer to Table 1.

\section{Hypothesis 2}

In the second hypothesis, no significant differences were expected to be found in perceptions of the three groups when testing professional counselors. As with the first hypothesis, a one-way analysis of variance was run for each of the four dependent variables (commitment, satisfaction, investment, and closeness). Contrary to the hypothesis, significant differences between the groups were found for satisfaction, $F(2,93)=5.21, p<0.01$, and investments, $F(2,92)=7.95, p<0.001$, and marginal significance was found for commitment, $F(2,92)=3.04, p=$. 053. Interestingly, the gay couple was perceived as the most satisfied, the lesbian couple slightly less satisfied, and the heterosexual couple as the least satisfied. The same pattern held true for investments. The gay couple was perceived to be the most invested, followed by the lesbian couple, with the heterosexual couple perceived as significantly less invested than either the gay or lesbian couple. For commitment, the lesbian couple was rated as the 
most committed, followed by the gay couple, and the heterosexual couple rated with the lowest level of commitment.

As with the student population, no significant differences were found among groups in perceived closeness. Although the differences were not statistically significant, $F(2,82)=1.27, p=0.27$, the trend in means showed a similar pattern as the other dependent variables, with the heterosexual couple being perceived to have the lowest level of closeness (refer to Table 1).

\section{Hypothesis 3}

The third hypothesis conjectured that there would be a significant difference in the levels of perceived commitment, satisfaction, investments, and closeness for the gay male and lesbian groups in the student sample, compared to the counselor sample. Paired samples t-tests were completed for each dependent variable.

For the first experimental group (gay male couple), there was a significant difference in the level of investments perceived by the student population and the counselor population, $t(105)=-2.21, p=0.03$. The difference in perceived commitment was marginally significant, $t(105)=-1.87, p=0.06$. The difference in closeness was also marginally significant, $t(101)=-1.75, p=0.08$. No significant difference was found for perceived levels of satisfaction. In sum, for investments, commitment, and closeness, the counselors perceived the gay couple to have at least marginally higher levels of these variables than did the student sample.

Perceived closeness was the only significant difference in the second experimental group (lesbian couple), $t$ $(95)=-2.65, p<0.01$. Again, the counselors perceived the lesbian couple to have a higher level of closeness than did the student sample.

Table 1. Mean Responses of Commitment, Satisfaction, Investment, and Closeness

\begin{tabular}{|c|c|c|c|c|}
\hline \multirow[b]{2}{*}{$\begin{array}{l}\text { Independent } \\
\text { Variables } \\
\end{array}$} & \multicolumn{2}{|c|}{ Student } & \multicolumn{2}{|c|}{ Counselor } \\
\hline & Mean & $\begin{array}{c}\text { Standard } \\
\text { Deviation }\end{array}$ & Mean & $\begin{array}{c}\text { Standard } \\
\text { Deviation }\end{array}$ \\
\hline & \multicolumn{4}{|c|}{ Commitment } \\
\hline Control & 5.01 & 0.99 & 4.71 & 1.06 \\
\hline Gay & 4.82 & 1.00 & 5.18 & 0.86 \\
\hline \multirow[t]{2}{*}{ Lesbian } & 5.03 & 0.93 & 5.30 & 0.96 \\
\hline & \multicolumn{4}{|c|}{ Satisfaction } \\
\hline Control & 3.77 & 0.91 & 3.22 & 0.65 \\
\hline Gay & 3.84 & 1.11 & 3.95 & 0.86 \\
\hline \multirow[t]{2}{*}{ Lesbian } & 3.83 & 1.15 & 3.67 & 1.08 \\
\hline & \multicolumn{4}{|c|}{ Investment } \\
\hline Control & 4.89 & 1.06 & 4.49 & 0.88 \\
\hline Gay & 4.85 & 1.09 & 5.32 & 0.86 \\
\hline \multirow[t]{2}{*}{ Lesbian } & 4.88 & 0.98 & 5.23 & 0.82 \\
\hline & \multicolumn{4}{|c|}{ Closeness } \\
\hline Control & 3.67 & 1.56 & 4.12 & 1.67 \\
\hline Gay & 3.90 & 1.60 & 4.48 & 1.38 \\
\hline Lesbian & 3.90 & 1.48 & 4.78 & 1.42 \\
\hline
\end{tabular}




\section{Discussion}

The results of this study were surprising on a number of points. First, because prior research had found that gay males were perceived as having less emotional involvement in relationships 5,20 , it was expected that in this study the student sample would perceive the gay male couple as having the least amount of commitment, satisfaction, investments, and closeness. However, this was not the case as the student sample did not perceive any significant differences between the groups.

It is suspected that the insignificance found in the students' perceptions between groups might have been due to the type of instrument used. The Likert scale used in rating the levels of relationship commitment, satisfaction, and investments was designed such that the number 1 was labeled very unlikely, the number 4 was labeled neutral, and the number 7 was labeled very likely. The student responses for all groups tended to stay near the value of four. It is possible then that the students may have opted to remain "neutral" in general, rather than infer a conclusion about any of the couples. This did not seem to be an issue with the counselor population. Perhaps their professional position allowed them more confidence in asserting a position on the quality of relationship for the couples.

Secondly, the counselors were not expected to perceive any differences between the groups. This assumption was made because of the specialized training counselors receive, and the higher level of education ${ }^{32}$. Just as in the first hypothesis, the results of the study tended to be opposite of those theorized. The counselor group did perceive a difference between the gay, lesbian, and heterosexual couples. Even more surprising is the fact that the non-heterosexual couples were perceived to be more committed, satisfied, and invested in their relationship than was the heterosexual couple.

Finally it was hypothesized that students and counselors would perceive different levels of commitment, satisfaction, investments, and closeness in gay, lesbian, and heterosexual couples when these two groups of participants were compared to each other. This hypothesis was supported, but again contrary to the expected direction. The student group perceived lower levels of commitment, investment, and satisfaction for the gay couple than did the counselor group. However, this was not due to the fact that the students perceived the gay couple as having any less of these traits than the heterosexual or lesbian couple. Instead the difference in the groups appears to come from the counselors perceiving the gay couple as being more committed, invested, and satisfied than the other two conditions. The same holds true with the lesbian couple being perceived by the counselors as having greater levels of closeness than did the student group.

The results of this research are especially noteworthy for the field of counseling psychology. All groups of clientele have the right to expect their relationship with a professional counselor or therapist to be free of prejudice that might affect the quality of care they receive ${ }^{9,4}$. This is true regardless of whether the prejudice is positive or negative. A gay or lesbian couple should reasonably expect to receive the same level of care as a heterosexual couple. However, the results of this study imply that may not be the case. It could be inferred that some counselors may be withholding negative feedback from gay and lesbian clients in order to avoid the appearance of bias.

At first it would seem that these responses might be the result of impression management for greater social desirability on the part of the participants. However, the only instances where social desirability was correlated with the participants' perceptions of the couple disprove this possibility. Impression management was found to be significantly correlated with the professional counselor group's perceived level of satisfaction for the couples. However, the correlation was negative in nature, so that the higher the level of impression management, the lower the level of perceived satisfaction. Secondly, this trend held true for the control group as well as the experimental groups.

It was not unreasonable to expect that the gay and lesbian couples would be perceived as less committed, satisfied, invested, and close to their relationship or partner. Even though studies have shown no real differences in levels of the aforementioned qualities in gay and lesbian relationships compared to heterosexual relationships, previous research has shown that heterosexist tendencies in our society result in non-heterosexual couples being viewed less favorably ${ }^{7,24}$. Moreover, non-heterosexual relationships are faced with additional stressors not felt by heterosexual couples. Fear of prejudice against their sexual orientation, internalized homophobia, and having a relationship that cannot be legally recognized are a just a few of the stressors with which gay and lesbian couples must deal ${ }^{1}$. Looking back on the results now, it is possible that the professional counselors may be aware of these stressors for homosexual couples, and therefore might infer that couples who stay together in spite of these societal hurdles have stronger levels of commitment (i.e., if you stay together through all of this, you must really be in love).

These additional stressors were noted by only five of the counselors who responded to the survey. Ninetythree of the 96 counselor respondents listed a number of possible issues they felt the couple would be dealing with. However, even though 69 of those respondents read about the gay or lesbian couple, only five noted that sexual orientation might play a role in their current relationship issues. Interestingly, of the five counselors who mentioned sexual orientation when listing the issues that the couple was facing, two self-identified as homosexual, one as 
bisexual, and two as heterosexual. Examples of the types of comments these few counselors made include: "possible homophobia may also be involved," "societal pressures on gay relationship (e.g., David may not feel comfortable asking for time off for anniversary because he doesn't disclose his gay relationship at work, or this is not perceived as a 'real' anniversary)," and, "with gay couples anniversary could mean anniversary of the day they met, their first date, the day they moved in together, or the day of a commitment ceremony, it doesn't imply marriage." To be fair, it should be emphasized that the transcript was designed in such a way that sexual orientation was not implicated as a stressor by the couple.

\section{Implications for Future Research}

The results of this research are intriguing and warrant further study in this area. However, there are a few areas in which future researchers on this topic could improve. First, the measure used to assess perceived commitment, investment, and satisfaction could be improved in two ways. By removing the option of "neutrality" in the responses, future researchers might be able to avoid the unvaried responses seen in this research from the student group. If these results were replicated in future research with a modified Likert scale, the results could more strongly support the notion that the group honestly did not perceive any differences between the conditions. Second, the scale used in this research rated how likely the participant felt the statement was. A number of the counselor participants noted on their survey that the wording of these questions made them difficult to respond to. To prevent this in the future, it might be more beneficial to word the statements for levels of agreement rather than likelihood (e.g., change from "How likely is it that this couple has a relationship that is close to their ideal?" to, "This couple has a relationship that is close to their ideal").

Further research may also benefit from using a transcript that is more in-depth. A number of the counselor respondents noted on their survey that they felt that the transcript was too short for them to confidently respond to the questions asked about the couple. In doing this, it might increase the likelihood of counselors responding to the survey. Although the response rate of $9.6 \%$ for this research was close to what can be expected for an unsolicited survey, even a small increase in number of responses would help bolster the statistical significance. In addition, we have no way of knowing differences between people who did respond and those who did not.

It might be beneficial to gather responses from a captive audience of professional counselors. This would minimize the chance of allowing respondent bias to affect the results. In the current study it is difficult to generalize the counselor responses to all professional counselors because we cannot rule out the possibility that those counselors who responded to the gay and lesbian conditions were not generally more prone to a positive prejudice towards gays and lesbians. In this case, it would also be useful for future researchers to gather data on how frequently the counselor works with non-heterosexual clients, as individuals and as couples.

Finally, future research would benefit from a sample that is more ethnically diverse (recall that both of the current samples are primarily White). It is possible that a different pattern of results would arise from minority participants; not only would this sample be more representative of the population, but individuals with any minority status in the U.S. may have greater insight into the issues such as prejudice which may be perceived as affecting the experimental couples in this research.

\section{Conclusion}

The field of research in gay, lesbian, bisexual, and transgender studies is growing steadily ${ }^{16,24}$. It is important that researchers in the social sciences continue research of this nature, not only for the benefit of those individuals in the gay and lesbian communities, but for society in general. In order to better understand gay and lesbian couples we must also understand how they are perceived. We encourage future researchers to continue work in this area.

\section{Acknowledgements}

The authors would like to thank Mary Pritchard, PhD for her help in reading an earlier draft of this work. We would also like to express our appreciation to David Hall and Helen Barnes for their support and input for this research. 


\section{References}

[1] Adams, J. A., Jaques, J. D., \& May, K. M. (2004). Counseling gay and lesbian families: Theoretical considerations. The Family Journal: Counseling and Therapy For Couples and Families, 12, 40-42. doi: $10.1177 / 1066480703258693$

[2] Agnew, C. R., Van Lange, P. A. M., Rusbult, C. E., \& Langston, C. A. (1998). Cognitive interdependence: Commitment and the mental representation of close relationships. Journal of Personality and Social Psychology, 74, 939-954.

[3] Aron, A., Aron, E. N., \& Smollan, D. (1992). Inclusion of Other in Self Scale and the structure of interpersonal closeness. Journal of Personality and Social Psychology, 63, 596-612. doi: 10.1037/0022-3514.63.4.596

[4] Association for Marriage and Family Therapy. (2001). AAMFT Code of Ethics. Retrieved October 2006, from http://www.aamft.org/resources/LRMPlan/Ethics.ethicscode2001.asp.

[5] Blumstein, P., \& Schwarts, P. (1983). American couples: Money, work, sex. New York: William Morrow.

[6] Crowne, D. P., \& Marlowe, D. (1960). A new scale of social desirability independent of psychopathology. Journal of Consulting Psychology, 24, 349-354. doi: 10.1037/h0047358

[7] De Cecco, J. P. (1988). Gay relationships. New York: Hawthorn Press.

[8] Dufty, S.M., \& Rusbult, C. E. (1986). Satisfaction and commitment in homosexual and heterosexual relationships. Journal of Homosexuality. 12(2), 1-24. doi: 10.1300/J082v12n02 01

[9] Egan, G. (2002). The skilled helper (7 th $^{\text {ed.). } . ~ A u s t r a l i a: ~ B r o o k s / C o l e . ~}$

[10] Eliason, M. J. (1997). The prevalence and nature of biphobia in heterosexual undergraduate students. Archives of Sexual Behavior, 26, 317-326.

[11] Florack, A., Scarabis, M., \& Gosejohann, S. (2005). The effects of self-image threat on the judgment of outgroup targets. Swiss Journal of Psychology - Schweizerische Zeitschrift für Pschologie - Revue Suisse de Psychologie, 64, 87-101. doi: 10.1024/1421-0185.64.2.87

[12] Gottman, J. M., Levenson, R.W., \& Gross, J. (2003). Correlates of Gay and Lesbian Couples' Relationship Satisfaction and Relationship Dissolution. Journal of Homosexuality, 45(1), 23-43. doi: 10.1300/ J082v45n01_02

[13] Hewitt, E. C., \& Moore, L. D. (2002). The role of lay theories of the etiologies of homosexuality in attitudes towards lesbians and gay men. Journal of Lesbian Studies, 6, 59-72.

[14] Institute for Sex Research \& Kinsey, A. C. (1953). Sexual behavior in the human female. Philadelphia: Saunders. doi: 10.1300/J155v06n02 07

[15] Israel, T., \& Hackett, G. (2004). Counselor education of lesbian, gay, and bisexual issues: Comparing information and attitude exploration. Counselor Education and Supervision, 43, 179-191.

[16] Jellison, W. A., McConnell, A. R., \& Gabriel, S. (2004). Implicit and explicit measures of sexual orientation attitudes: Ingroup preferences and related behaviors and beliefs among gay and straight men. Personality and Social Psychology Bulletin, 30, 629-642. doi: 10.1177/0146167203262076

[17] Kinsey, A. C., Pomeroy, W. B., \& Martin, C. E. (1948). Sexual behavior in the human male. Philadelphia: W. B. Saunders Co.

[18] Klien, F. (1985). Bisexualities: Theory and research. New York: Hawthorn Press.

[19] Kurdek, L.A. (1998). Relationship outcomes and their predictors: Longitudinal evidence from heterosexual married, gay cohabiting, and lesbian cohabiting couples. Journal of Marriage and Family, 60, 553-568. doi: $10.2307 / 353528$

[20] Lamar, L., \& Kite, M. (1998). Sex differences in attitudes towards gay men and lesbians: A multidimensional perspective. The Journal of Sex Research, 35, 189-196.

[21] Linville, P. W., Salovey, P., \& Fischer, G. W. (1986). Stereotyping and perceived distributions of social characteristics: An application to ingroup-outgroup perception. In J. F. Dovidio \& S. L. Gaertner (Eds.), Prejudice, discrimination, and racism (pp. 165-208). San Diego: Academic Press.

[22] McWhirter, D. P., Sanders, S. A. Reinisch, J. M. (1990). Homosexuality/heterosexuality: Concepts of sexual orientation. New York: Oxford University Press.

[23] Mohr, J. J., Israel, T., \& Sedlacek, W. E. (2001). Counselors' attitudes regarding bisexuality as predictors of counselors' clinical responses: An analogue study of a female bisexual client. Journal of Counseling Psychology, 48, 212-222. doi:10.1037/0022-0167.48.2.212

[24] Morrison, M. A., \& Morrison, T. G. (2002). Development and validation of a scale measuring modern prejudice toward gay men and lesbian women. Journal of Homosexuality, 43, 15-37. doi:10.1300/J082v43n02_02

[25] Paulhus, D. L. (1991). Measurement and control of response bias. In J. P. Robinson, P.R. Shaver, L. S. Wrightsman, \& F. M. Andrews (Eds.), Measures of personal and social psychological attitudes (Vol. 1, pp. 
[26] Peplau, L. A. (1990). Relationship perspective. In D. P. McWhirter, S. A. Sanders, J. M. Reinisch (Eds.), Homosexuality/heterosexuality: Concepts of sexual orientation (Vol. 2, pp. 321 - 349). New York: Oxford University Press.

[27] Peplau, L. A., Padesky, C., \& Hamilton, M. (1982) Satisfaction in lesbian relationships. Journal of Homosexuality, 8, 23-35. doi:10.1300/J082v08n02_04

[28] Ramsey, J., Latham, J. D., \& Linquist, C. U. (1978, August). Long term same-sex relationships: Correlates of adjustment. Paper presented at the annual meeting of the American Psychological Association, Toronto, Canada.

[29] Rusbult, C. E., Martz, J. M., \& Agnew, C. R. (1998). The investment model scale: Measuring commitment level, satisfaction level, quality of alternatives, and investment size. Personal Relationships, 5, 357-391.

[30] Spears, R., Gordijn, E., Dijksterhuis, A., \& Stapel, D. A. (2004). Reaction in action: Ingroup contrast in automatic behavior. Personality and Social Psychology Bulletin, 30, 605-616. doi: $10.1177 / 0146167203262087$

[31] Social Security Administration (2005). Popular baby names. Retrieved February 2006. from http://www/ssa/ gov/OaCT/babynames/.

[32] Vicario, B. A., Liddie, B. J., \& Luzzo, D. A. (2005). The role of values in understanding attitudes toward lesbians and gay men. Journal of Homosexuality, 49, 145-159. doi:10.1300/J082v49n01_07 